\title{
Porcupine Bank: the superficial sediments and their fauna
}

\author{
G. Bowes \\ Department of Applied Geology, Strathclyde University, Glasgow
}

and

\section{S. M. Smith}

Royal Scottish Museum, Edinburgh

The superficial sediments of the Porcupine Bank have been classified according to their grain size and composition - the proportions of lithic materials, pelagic or benthic Foraminifera, other calcareous materials of benthic origin (Bryozoa, Mollusca, Cirrepedia). Four main facies have been identified. Living fauna was collected concomitantly and photographic evidence was obtained from a few stations. Communities have been recognised and the interaction of the substrate and the fauna has been considered.

1. In the deep water area to the west of Porcupine Bank there are considerable areas of outcrop. The superficial sediments are composed of abundant pebbles together with mud, which is dominated by pelagic Foraminifera, with lesser amounts of lithic sand and some benthic Foraminifera. The fauna obtained from this area is largely that of a shell gravel/pebble-based community dominated by Limopsis aurita, Astarte sulcata and Brachiopoda. The finer sediments have an Ophiothrix lutkeni community. Overall there is a high calcium demand with recycling of dead shells and input from pelagic Foraminifera.

2. The southwestern part of the bank has less than $50 \%$ lithic material but this, nevertheless, is the most abundant single component. The other components are mainly pelagic and benthic Foraminifera. Although pebbles have an immediate local effect on the total faunal composition, the muds and silts of this area have a clear pennatulid, Hyalinoecia tubicola and Abra longicallus community. Animals were generally rather sparse.

3. The sand-floored crescent around the northern and southern flanks of the bank have over $50 \%$ lithic component (in some areas up to $75 \%$ ) with the rest composed of benthic and pelagic Foraminifera in more or less equal amounts. The area is characterised by a diverse fauna living on the firm sand, including Actinauge richardii, pagurids, Gonoplax rhomboides, Astropecten irregularis, echinoids, Scaphander lignarius etc. Photographs indicate that deep-burrowing Crustacea are abundant.

4. The finer sediment in the boulder field on the top of the bank has a matrix of carbonate sand whose constituents are Mollusca, benthic Foraminifera and only $15-45 \%$ lithic material. On the crest there are conspicuous amounts of fragments of Bryozoa, serpulids and Gastropoda. The fauna is the most diverse found, the hard sand communities being added to by those dominated by encrusting species living on the boulders, such as sponges, Bryozoa, serpulid 
worms. There is a larger proportion of animals with high calcium demand. Grain size has proved to be of more importance in determination of the community than depth. Carbonate input is also important. Below a certain concentration of shelled animals, above which a shell gravel may be maintained without difficulty, the bottom sediments may have a very low carbonate content with shelly material coming mainly from Foraminifera. Field observations suggest that where shell is at a premium, upon the death of its maker it would be promptly colonised as a substrate from which carbonate could be extracted by a new arrival or as a home to pagurids, often one of the commoner species in such conditions. They live in gastropod shells until these fall to bits (very few empty gastropod shells were found). Shell fragments disintegrate to about $2 \mathrm{~mm}$ and then completely collapse. The absence of carbonate in the sediments indicates that it is very rapidly recycled into living organisms. Some differences in community structure between facies 3 and facies 4 may be attributable not only to grain size but also to the amount of calcium available.

\title{
A multiple corer for taking virtually undisturbed samples from shelf, bathyal and abyssal sediments
}

\author{
P. R. O. Barnett, J. Watson and D. Connelly \\ Dunstaffnage Marine Research Laboratory, P.O. Box 3, Oban, Argyll PA34 4AD, \\ Scotland
}

Reliable samples are essential for accurate measurements of population densities, standing crops and energy flow. When sampling benthic meiofauna, it is necessary to sample the surface layer of the sea bed without disturbing or wafting it aside first before the sampler hits the bottom. It is well-known that most benthic samplers have serious deficiencies, yet the results obtained with them are frequently subjected to sophisticated techniques of statistical analysis. The problems of "bow-wave" effects when sampling the benthos have been emphasised by various authors for macrobenthos, meiobenthos and sedimentation rate and pollution studies.

Except for coring by divers, there is only one design of core sampler capable of taking a virtually undisturbed surface sediment sample; the Craib (1965) corer slowly lowers a plastic sampling tube into the sediment under the control of a hydraulic damper. Although this corer is very successful when used in sheltered inshore waters, there are considerable difficulties in obtaining samples from continental shelf and deep-sea sediments because valve-closing mechanisms are adversely affected by open sea conditions. Other alternatives for meiofaunal sampling include the use of benthic macrofaunal samplers (e.g. van Veen grabs, Reinek box corers) and subsequent subsampling by hand with small core tubes when the large sample has been recovered on deck. However, it has been shown that subsampling the van Veen grab will not give truly quantitative results; only subsampling in a box corer may be considered a quantitative method, although 